\title{
Detection of various beta lactamases in gram negative bacteria and their resistance pattern in northern India
}

\author{
Khanna $\mathrm{A}^{\mathbf{1}}$, Khanna $\mathbf{M}^{2}$, Sharma $\mathrm{S}^{3}$ \\ ${ }^{1}$ Dr. Ashish Khanna, Associate Professor, Microbiology, ${ }^{2}$ Dr. Menka Khanna, Professor, Pathology, ${ }^{3}$ Dr Sarabjit Sharma, \\ Professor and Head, Department of Microbiology; all authors are affiliated with Sri Guru Ram Das Institute of Medical \\ Sciences and Research, Amritsar.
}

Address for Correspondence: Dr Ashish Khanna, 538, Basant Avenue, Amritsar (Punjab), India. E-mail ID: ashish_538@yahoo.co.in

\begin{abstract}
Background: Resistance to broad spectrum beta lactam antibiotics due to ESBL/AmpC/MBL enzymes is an increasing problem worldwide. Estimation of their prevalence in the area is essential to formulate an effective antimicrobial policy for a particular hospital/area. Aim: The present study was done to know the prevalence of ESBL/AmpC/MBL in gram negative organisms isolated from clinical samples and their susceptibility pattern in a tertiary care hospital in northern India. Methods: Total of 160 isolates of gram negative organisms from clinical specimens were screened for the presence of various beta lactamases by standard phenotypic methods and their antibiotic susceptibility pattern to conventionally used antibiotics was determined by disc diffusion method as per CLSI guidelines. Results: 118 gram negative isolates showing reduced susceptibility to third generation cephalosporin's were screened for ESBL/ AmpC/ MBL production. Beta lactamase production was seen in 74 out of the 160 gram negative isolates obtained from different samples. ESBL production alone or in combination with AmpC/MBL is seen in 60 isolates. ESBL/ AmpC and ESBL/ MBL coproduction was seen in $9(5.6 \%)$ and $3(1.9 \%)$ of the isolates respectively. Multi drug resistance was significantly higher in beta lactamase producers than non lactamase producers. Conclusions: There is need for continuous surveillance in the hospitals for the detection of various beta lactamases or resistant strains. Strict guidelines should be followed for antibiotic therapy so as to reduce burden of antibiotic resistance. Further phenotypic and genotypic studies should be undertaken to know the resistance pattern in bacteria.
\end{abstract}

Keywords: ESBL, AmpC, MBL, Beta lactamases

\section{Introduction}

Extended spectrum beta lactamases (ESBL) are protective enzymes produced by Gram negative bacteria which make them resistant to third generation cephalosporin e.g. ceftazidime and cefotaxime. They also make the organism resistant to penicillins as well as other classes of antibiotics thus making treatment options difficult. ESBL do not destroy cephamycin and their effect is blocked by clavulanic acid [1]. AmpC enzymes are again produced by gram negative bacteria but inhibition by clavulanic acid is poor in them. They make the organism resistant to cephalosporin, $\alpha$ methoxy $\beta$ - lactams (cefoxitin etc) and monobactam like aztreonam. They have no effect on cefepime and cefepirome. This different action on cephamycins and

Manuscript received: $24^{\text {th }}$ August 2016

Reviewed: $5^{\text {th }}$ September 2016

Author Corrected: $18^{\text {th }}$ September 2016

Accepted for Publication: $30^{\text {th }}$ September 2016 b-lactamase inhibitors differentiates AmpC enzymes positive organisms from the ESBL producers [2]. Chromosomal or plasmid mediated resistance is the most common method of resistance in them. Carbapenems were the only hope for infections with these resistant bacteria. However this last barrier was also broken by carbapenemases (MBL) enzymes that started emerging worldwide and were able to destroy carbapenems. The metallo $\beta$-lactamase in Gram negative bacteria are a challenge to the clinician as they destroy most of the known $\beta$-lactam antibiotics including carbepenems [3].

For the effective treatment of infections with these resistant organisms, their early detection and revised treatment schedule accordingly should be instituted promptly. But their detection in ordinary laboratory is 
not possible as various tests are required for their detection. Infections caused by these organisms are increasing very rapidly which is making the empiric therapy for these common infections ineffective. The magnitude of the resistance problem also depends upon the misuse of the antibiotics prevalent in that geographic area. Poverty, high circulation of substandard antibiotics as well as illiterate population in our country are all contributory factors for this health problem. High incidence of resistance leads to management problem in these gram negative infections [4].

As there is insufficient data regarding expression of extended spectrum beta lactamases, AmpC and metallo$\beta$-lactamases by gram negative bacterial strains causing infections in Punjab in northern India. Therefore not much information is available on resistance pattern of gram negative bacteria in northern India. Consequently, area specific studies to see for their prevalence in the society is the need of the hour. On the basis of these studies empiric therapy for these resistant bacteria can be altered accordingly [5]. So the study was done to calculate the prevalence of beta lactamases produced by gram negative bacteria prevalent in northern part of India so as to help clinician in formulating an effective empiric therapy.

\section{Materials and Methods}

The study was done in Sri Guru Ram Das Institute of Medical Sciences and Research over a period of six months (July to December 2014) to calculate the burden of ESBL and AmpC/MBL producing strains among gram negative isolates from the various wards of the hospital. The gram negative strains isolated from different clinical specimens such as urine, pus, blood and body fluids were included in our study. These bacterial strains were identified by conventional culture and biochemical characters as per set standard technique [6].

Mueller Hinton agar (HiMedia) was used for doing the susceptibility testing by the disc diffusion method as per CLSI guidelines [7]. The following antibiotics of standard potency were used: ceftazidime, cefotaxime, cefepime, cefoxitin, ceftriaxone, meropenem, and imipenem, Piperacillin, amikacin, netilmicin, gentamicin, ciprofloxacin, piperacillin/ tazobactam, ticarcillin / clavulanic acid.

All bacterial isolates having reduced sensitivity to ceftazidime (zone diameter of $<22 \mathrm{~mm}$ ), ceftriaxone (zone diameter of $<25 \mathrm{~mm}$ ) or cefotaxime as per CLSI guidelines were included in the study. These were further confirmed for the ESBL production by doubledisc diffusion method and double disc synergy test by using E. coli ATCC 25922 as control.

After swabbing the isolates on muller hinton plate disc of ceftazidime and ceftazidime + clavulanic were placed apart. The plates were incubated at $37^{\circ} \mathrm{C}$ for 24 hours. After incubation $>5 \mathrm{~mm}$ difference in the inhibition zone of ceftazidime + clavulanic acid disc as compared to ceftazidime disc alone was taken as ESBL positive. This was further confirmed by Triple ESBL Ezy MIC strip (himedia).

This E strip contains a mixture of three different antibiotic with or without inhibitors like clavulanic acid in a concentration gradient. The strains having ratio of $>$ 8 when the MIC of mixture plus and mixture is compared respectively are taken as ESBL positive.

Each isolate showing decreased sensitivity to ceftazidime, ceftriaxone, cefotaxime was swabbed on muller hinton plate and disc of and cefoxitin and cefoxitin + aminophenyl boronic acid were placed more than $30 \mathrm{~mm}$ apart. The plates were incubated at $37^{\circ} \mathrm{C}$ for 24 hours.

After incubation $>5 \mathrm{~mm}$ increase in inhibition zone of cefoxitin plus aminophenyl boronic acid (APBA) disc as compared to cefoxitin alone was taken as positive for AmpC. Further these isolates were tested with modified three dimensional test and flattening of the inhibition zone confirmed AmpC production [8].

All isolates were further tested for MBL production with the disc of imipenem and imipenem in combination with EDTA placed at a distance of $20 \mathrm{~mm}$ apart on a muller hinton plate which was incubated overnight at $37^{\circ} \mathrm{C}$. Difference in inhibition zone of $>7$ $\mathrm{mm}$ between the two was taken as positive for MBL production. $P$. aeruginosa ATCC 27853 was used as a negative control strain.

This was confirmed by MBL E-test ( HiMedia) which is coated with mixture of Imipenem plus EDTA in a concentration gradient. One half of the strip was coated with Imipenem plus EDTA whereas other half was coated with Imipenem in a concentration gradient. When the ratio of values obtained was more than or equal to 8 (or no zone is obtained for Imipenem and zone obtained for Imipenem plus EDTA) strains were considered as MBL producers [9]. 


\section{Results}

The total numbers of gram negative strains showing reduced sensitivity to third generation cephalosporins was 118 . Confirmatory tests for ESBL/ AmpC/ MBL production was performed on these isolates. Beta lactamase production was seen in 74 out of the 160 gram negative isolates obtained from different samples. Beta lactamase production was highest in klebsiella species 26/41 (63.4\%). Beta lactamase production was also high in non fermenters (acinetobacter) $7 / 12$ (58.3\%) and in pseudomonas species 6/14 (42.8). Table 1 The distribution of different beta lactamases in gram negative isolates is given in table 2. ESBL production alone or in combination with AmpC/MBL is seen in 60 isolates. ESBL/ AmpC and ESBL/ MBL coproduction was seen in 9 (5.6\%) and 3 (1.9\%) of the isolates respectively. Table II

Single beta lactamase (ie either ESBL or AmpC or MBL) was seen in 61/160 isolates and coproduction of beta lactamases ie either ESBL plus AmpC or ESBL plus MBL or AmpC plus MBL was seen in 13/160 isolates. Table 3 ESBL alone was seen in 48/160 (30\%) isolates. Again the highest no of ESBL was seen in klebsiella species 16/41 (39\%) followed by E. coli 23/76 (30.2\%).Table3 Antimicrobial resistance pattern of beta lactamase producers and non lactamase producers is shown in table 4. Multi drug resistance was significantly higher in beta lactamase producers than non lactamase producers.

Table 1: showing beta lactamase production in gram negative organisms.

\begin{tabular}{|c|c|c|c|}
\hline Organism & Total no & Beta lactamase producer & \% of total \\
\hline E coli & 76 & 30 & 39.47 \\
\hline Klebsiella & 41 & 26 & 63.41 \\
\hline Pseudomonas & 14 & 6 & 42.85 \\
\hline Non fermenter & 12 & 7 & 58.33 \\
\hline Citrobacter & 6 & 2 & 33.33 \\
\hline Proteus & 6 & 2 & 33.33 \\
\hline Enterobacter & 5 & 1 & 20.00 \\
\hline
\end{tabular}

Table 2: shows distribution of different beta lactamases among gram negative isolates.

\begin{tabular}{|c|c|c|}
\hline Type of enzyme & Positive & \% age of total(n=160) \\
\hline ESBL & 48 & 30.0 \\
\hline AmpC & 5 & 3.1 \\
\hline MBL & 8 & 5.0 \\
\hline ESBL+ AmpC & 9 & 5.6 \\
\hline ESBL+MBL & 3 & 1.9 \\
\hline AmpC+MBL & 1 & .6 \\
\hline ESBL+MBL+ AmpC & - & - \\
\hline
\end{tabular}

Table 3: showing ESBL/AmpC/MBL presence in various gram negative organisms.

\begin{tabular}{|c|c|c|c|c|c|c|}
\hline Organism & $\begin{array}{c}\text { ESBL } \\
\text { No(\%age) }\end{array}$ & $\begin{array}{c}\text { AmpC } \\
\text { No(\%age) }\end{array}$ & $\begin{array}{c}\text { MBL } \\
\text { No(\%age) }\end{array}$ & $\begin{array}{c}\mathrm{ESBL}+\mathrm{AmpC} \\
\mathrm{No}(\% \text { age })\end{array}$ & $\begin{array}{c}\text { ESBL+ } \\
\text { MBL } \\
\text { No(\%age })\end{array}$ & $\begin{array}{c}\text { AmpC+MBL } \\
\text { No(\%age })\end{array}$ \\
\hline E coli & $23(30.2)$ & $2(2.6)$ & $1(1.3)$ & $3(3.9)$ & $1(1.3)$ & - \\
\hline Klebsiella & $16(39.0)$ & $1(2.4)$ & $3(7.3)$ & $4(9.8)$ & $1(2.4)$ & $1(2.4)$ \\
\hline Pseudomonas & $2(14.3)$ & $1(7.1)$ & $2(14.3)$ & $1(7.4)$ & - & - \\
\hline Non fermenter & $3(25.0)$ & - & $2(16.7)$ & $1(8.3)$ & $1(8.3)$ & - \\
\hline Citrobacter & $1(16.7)$ & $1(16.7)$ & - & - & - & - \\
\hline Proteus & $2(33.3)$ & - & - & - & - & - \\
\hline Enterobacter & $1(20.0)$ & - & - & - & - & - \\
\hline
\end{tabular}


Research Article

Table 4: Antimicrobial resistance pattern of beta lactamase producers and non beta lactamase producers.

\begin{tabular}{|l|c|c|c|c|c|c|c|c|}
\hline Antibiotic & & & & & & & \\
\hline Antibiotic & $\begin{array}{c}\text { ESBL } \\
\mathrm{n}=48\end{array}$ & $\begin{array}{c}\mathrm{AmpC} \\
\mathrm{n}=5\end{array}$ & $\begin{array}{c}\text { MBL } \\
\mathrm{n}=8\end{array}$ & $\begin{array}{c}\text { ESBL+ } \\
\mathrm{AmpC} \\
\mathrm{n}=9\end{array}$ & $\begin{array}{c}\text { ESBL+ } \\
\text { MBL } \\
\mathrm{n}=3\end{array}$ & $\begin{array}{c}\text { MBL+ } \\
\text { AmpC } \\
\mathrm{n}=1\end{array}$ & $\begin{array}{c}\text { Total beta } \\
\text { lactamase } \\
\text { Producers } \\
\mathrm{n}=74\end{array}$ & $\begin{array}{c}\text { Non beta } \\
\text { lactamase } \\
\text { Producers } \\
\mathrm{n}=86\end{array}$ \\
\hline Amikacin & 17 & 1 & 3 & 2 & 1 & 0 & 24 & 16 \\
\hline Gentamycin & 36 & 2 & 6 & 6 & 2 & 1 & 53 & 40 \\
\hline Piperacillin & 40 & 4 & 4 & 6 & 2 & 1 & 57 & 30 \\
\hline Cefotaxime & 43 & 4 & 5 & 8 & 3 & 1 & 64 & 32 \\
\hline Ceftrioxone & 45 & 4 & 5 & 7 & 2 & 1 & 64 & 34 \\
\hline Ceftazidime & 48 & 5 & 4 & 9 & 3 & 1 & 70 & 38 \\
\hline Cefipime & 11 & 0 & 3 & 2 & 1 & 0 & 17 & 10 \\
\hline Cefoxitin & 0 & 5 & 4 & 9 & 0 & 1 & 19 & 8 \\
\hline Ciprofloxacin & 32 & 4 & 6 & 6 & 3 & 1 & 52 & 36 \\
\hline P/T & 2 & 4 & 5 & 5 & 1 & 0 & 17 & 8 \\
\hline T/C & 2 & 4 & 5 & 4 & 1 & 0 & 16 & 9 \\
\hline Imipenem & 0 & 0 & 8 & 0 & 3 & 1 & 12 & 0 \\
\hline
\end{tabular}

\section{Discussion}

Multidrug resistant gram negative bacteria are emerging worldwide, challenging the clinicians, public health professionals, and hospital infection-control teams. There is a lower level of awareness of ESBLs and other enzymes like AmpC and MBL produced by gram negative bacteria among the clinicians as well as laboratory technicians or pathologists conducting the tests in the laboratories. Confusion persists regarding the test to be put up for their detection as well as regarding the available treatment options against them. Thus failure to promptly detect them has lead to their increased prevalence along with treatment failure when these enzymes are present [3]. The phenomenon of increasing resistance is seen worldwide but is more in our country with limited resources at our disposal for health related activities. The incidence of ESBL, AmpC and MBL producing strains among gram negative isolates has been increasing alarmingly leading to limited therapeutic alternatives. These enzymes are either plasmid or chromosomally mediated and can be easily transferred to other bacteria lacking them [10].

Previously it was reported by various researchers that these enzymes were mostly seen in E coli and Klebsiella species. However in recent times there have been reports of these enzymes being produced by all bacteria of family Enterobactericeae as well as other gram negative bacteria [11]. In India, the burden of ESBL, AmpC beta lactamase and MBL producers vary from various hospitals, different wards and even between various sites of infections such as urinary tract infections and wound infections etc. However, most of the hospitals in India are lacking accessibility to prevailing antimicrobial susceptibility patterns. This may results in the inappropriate prescription of antibiotics for empirical treatments [11-13]. In view of these issues, the present study was designed to assess the current levels of resistance to antibiotics that are commonly used in our hospital and also to review the prevalence of ESBL, AmpC beta lactamase and MBL production among various gram negative bacterial isolates.

In the current study, the incidence of ESBL producing organisms was found to be $60(38.9 \%)$. In India the prevalence of ESBL production in gram negative isolates varies among different regions as well as different hospitals in the same region. Prevalence data varies from as low as $6.6 \%$ to as high as $68 \%$ [11-12]. However, this rate was comparable to the previous investigations carried out in the other regions of the country [13]. This reduced ESBL production among the gram negative isolates could be attributed to the judicious use of cephalosporins and good infectioncontrol measures in our hospital.

The common isolates which are becoming resistant due to AmpC also belong to Ecoli and Klebsiella species among the family enterobacteriaceae. These strains are increasing becoming resistant to third generation 
cephalosporins and cephamycins. Due to this high treatment failures with cephalosporins have been seen [14]. In a study in Virginia AmpC enzymes were found to be $1.2 \%$ in family enterobacteriaceae whereas we found the rate to be higher ie $15(9.8 \%)$ [15]. In our study the AmpC $\beta$-lactamases production was comparable to that of Singhal et al (8\%) [16].

However it was lower than the other documented study in India [17]. This combination of various beta lactamases also pose a serious challenge for the diagnostic laboratories as well as the clinician. This coexistence of AmpC as well as ESBL in gram negative organisms was seen in $9(5.6 \%)$ cases. This could be due to the transfer of plasmids containing genes for both Amp C and ESBL enzymes between members of the family enterobacteriaceae.

The lower level of the AmpC producers in our study could be due to the differences in the geographical distribution. Carbapenems were the only treatment option for these coproducers of enzymes. But nowadays carbapenem resistant strains have been seen which is mostly due to MBL production. In our study, the MBL producers were 14 (8.8\%). Our findings have similarities with the study which was done by Datta et al, who reported $7.8 \%$ MBL producers [18].

The coexistence of ESBL and MBL was reported in $1.9 \%$ isolates, whereas the $\mathrm{AmpC}$ and the MBL co production was shown by $0.6 \%$ isolates and the $\mathrm{AmpC}$ and the ESBL co production was shown in $5.6 \%$ isolates. Table 2

In our study, the multidrug resistant strains showed co resistance to the fluoroquinolones and aminoglycosides along with the beta lactam antibiotics. But they were mostly susceptible to imipenam and the piperacillintazobactem combination, which was in concordance with the findings of similar study in the Indian subcontinent [12].

A number of tests have been done for the detection of beta lactamases. but the phenotypic tests are affordable and easy to perform than the genotypic tests. These tests are further divided into screening and confirmatory tests. Ceftazidime was found to be most effective among cephalosporins for detection of potential ESBL producers as seen in other reports also [19].

Incidence of multi drug resistance was significantly higher $(\mathrm{p}<.05)$ in isolates producing beta lactamases than isolates which are non beta lactamase producers.
Table IV Carbapenem are the effective treatment options for the various beta lactamase producers but for MBL producers polymyxin B and colistin are the only option left for the clinician [16].

So every hospital should plan the empiric therapy after seeing the incidence of beta lactamases in their wards.

Failure to do that would lead to treatment failure and high mortality among the patients [17-19].

Funding: Nil, Conflict of interest: None initiated, Permission from IRB: Yes

\section{Bibliography}

1. Shoorashetty RM, Nagarathnamma T, Prathibha J. Comparison of the boronic acid disk potentiation test and cefepime-clavulanic acid method for the detection of ESBL among AmpC-producing Enterobacteriaceae. Indian J Med Microbiol. 2011 Jul-Sep;29(3):297-301. doi: 10.4103/0255-0857.83917.

2. Jacoby GA. AmpC beta-lactamases. Clin Microbiol Rev. 2009 Jan;22(1):161-82, Table of Contents. doi: 10.1128/CMR.00036-08.

3. Naas T, Cuzon G, Bogaerts P, Glupczynski Y, Nordmann P. Evaluation of a DNA microarray (CheckMDR CT102) for rapid detection of TEM, SHV, and CTX-M extended-spectrum $\beta$-lactamases and of KPC, OXA-48, VIM, IMP, and NDM-1 carbapenemases. J Clin Microbiol. 2011 Apr;49(4):1608-13. doi: 10.1128 /JCM.02607-10. Epub 2011 Feb 16.

4. Steinke DT, Seaton RA, Phillips G, Mac-Donald TM, Davey PG. Prior trimethoprim use and trimethoprimresistant urinary tract infection: a nested case-control study with multivariate analysis for other risk factors. J Antimicrob Chemother 2001;47(6):781-7.doi:10.1093/ jac/47.6.781.

5. Smith RD, Coast J. Antimicrobial resistance: a global response. Bull World Health Organ. 2002;80(2):126-33.

6. Collee JG, Miles RS, Wan B. Tests for the identification of bacteria. In: Collee JG, Fraser AG, Marmion BP, Simmons A, eds. Mackie and Mc Cartney Practical Medical Microbiology. $14^{\text {th }}$ ed. Edinburgh: Churchill Livingstone; 1996:131-50.

7. Wayne PA. Clinical and Laboratory Standards Institute. Performance Standards for Antimicrobial Susceptibility Testing; Twentieth Informational Supplement M100-S20; 2010. 


\section{Research Article}

8. Shahid M, Malik A, Agrawal M, Singhal S. Phenotypic detection of extended-spectrum and AmpC beta-lactamases by a new spot-inoculation method and modified three-dimensional extract test: comparison with the conventional three-dimensional extract test. J Antimicrob Chemother. 2004 Sep;54(3):684-7. Epub 2004 Aug 4.

9. Yong D, Lee K, Yum JH, Shin HB, Rossolini GM, Chong Y. Imipenem-EDTA disk method for differentiation of metallo-beta-lactamase-producing clinical isolates of Pseudomonas spp. and Acinetobacter spp. J Clin Microbiol. 2002 Oct; 40(10):3798-801.

10. Valsan C, Chinnan JP, Sathiavathy KA. Phenotypic detection of $\beta$-lactamases in enterobacreriaceae using a 12disk procedure. J Acad Clin Microbiol 2013;15(1):710.doi:10.4103/0972-1282.116090.

11. Mathur P, Kapil A, Das B, Dhawan B. Prevalence of extended spectrum beta lactamase producing gram negative bacteria in a tertiary care hospital. Indian $\mathbf{J}$ Med Res. 2002 Apr;115:153-7.

12. Subha A, Ananthan S. Extended spectrum $\beta$ lactamase (ESBL) mediated resistance to third generation cephalosporins among Klebsiella pneumonia in Chennai. Indian J Microbiol 2002; 20:92-5.

13. Bhattacharjee A, Anupurba S, Gaur A, Sen MR. Prevalence of inducible AmpC beta-lactamaseproducing Pseudomonas aeruginosa in a tertiary care hospital in northern India. Indian J Med Microbiol. 2008 Jan-Mar;26(1):89-90.

14. Doi Y, Paterson DL. Detection of plasmid-mediated class C beta-lactamases. Int J Infect Dis. 2007 May;11(3):191-7. Epub 2007 Mar 6.

15. Coudron PE. Inhibitor-based methods for detection of plasmid-mediated AmpC beta-lactamases in Klebsiella spp., Escherichia coli, and Proteus mirabilis. J Clin Microbiol. 2005 Aug;43(8):4163-7.

16. Singhal S, Mathur T, Khan S, Upadhyay DJ, Chugh S, Gaind R, Rattan A. Evaluation of methods for AmpC beta-lactamase in gram negative clinical isolates from tertiary care hospitals. Indian J Med Microbiol. 2005 Apr;23(2):120-4.

17. Arora S, Bal M. AmpC beta-lactamase producing bacterial isolates from Kolkata hospital. Indian J Med Res. 2005 Sep;122(3):224-33.

18. Datta P, Gupta V, Garg S, Chander J. Phenotypic method for differentiation of carbapenemases in Enterobacteriaceae: study from north India. Indian $\mathbf{J}$ Pathol Microbiol. 2012 Jul-Sep;55(3):357-60.doi: 10.4103/0377-4929.101744.

19. Cormican MG, Marshall SA, Jones RN. Detection of extended-spectrum beta-lactamase (ESBL)producing strains by the Etest ESBL screen. J Clin Microbiol. 1996 Aug;34(8):1880-4.

\section{How to cite this article?}

Khanna A, Khanna M, Sharma S. Detection of various beta lactamases in gram negative bacteria and their resistance pattern in northern India. Trop J Path Micro 2016;2(2):70-75.doi: 10.17511/jopm.2016.i02.06 